RU Способы реализации коммуникативных стратегий в коллективном речевом портрете современных немецких политиков
(на материале текстов протокольно-этикетных речей)

Цветкова Е. Б.

\begin{abstract}
Аннотация. Цель исследования - выявление релевантных способов лексической реализации речевых стратегий, лежащих в основе формирования коллективного и индивидуального речевых портретов ведущих политических деятелей Германии на материале их протокольно-этикетных речей. Научная новизна заключается в разработке типологии стратегий и тактик, характерных для протокольно-этикетных речей ведущих немецких политиков. В результате доказано, что в сфере протокольно-этикетных речей коллективный речевой портрет немецких политиков структурируется в процессе использования речевыми субъектами таких универсальных стратегий, как стратегия строгой регламентации речи, стратегия формирования позитивного эмоционального настроя, стратегия аргументации и стратегия кооперации, а также стратегии самопрезентации, нетипичной для классических протокольно-этикетных речей.
\end{abstract}

\title{
EN Ways for Implementing Communicative Strategies in Collective Speech Portrait of the Modern German Politicians (by the Material of Ceremonial Speeches Texts)
}

\section{Tsvetkova E. B.}

\begin{abstract}
The study aims to identify relevant ways for lexical implementation of speech strategies that underlie formation of collective and individual speech portraits of the leading German political figures basing on their ceremonial speeches. Scientific novelty of the study lies in developing a typology of strategies and tactics peculiar to ceremonial speeches of the leading German politicians. As a result, it is proved that in the sphere of ceremonial speeches, the collective speech portrait of the German politicians is structured in the process of using such universal strategies as the strategy of strict regulation of speech, the strategy of creating positive emotional mood, the strategy of argumentation and the strategy of cooperation, as well as the strategy of self-presentation, which is uncharacteristic of classical ceremonial speeches.
\end{abstract}

\section{Введение}

Актуальность темы исследования определяется его направленностью на основные проблемы современной антропоцентрически ориентированной лингвистики, изучающей роль человеческого фактора в процессе коммуникации. Кроме того, предметом повышенного интереса исследователей продолжают оставаться тексты, формирующиеся в рамках политического дискурса в ходе коммуникативной деятельности профессиональных политиков. Актуальным также следует считать апелляцию к понятию речевого портрета, реализация которого предполагает его существование в индивидуальной и коллективной формах.

Достижение указанной цели предполагает решение ряда задач: во-первых, определить место протокольно-этикетных речей в семантическом пространстве дискурса; во-вторых, осуществить типологию речевых стратегий и тактик, используемых немецкими политиками в протокольно-этикетных речах, в-третьих, проанализировать способы лексического выражения тактик.

При решении поставленных задач были реализованы следующие методы исследования: метод прагмалингвистического анализа, метод контекстуального анализа, метод количественного подсчета, а также приемы риторического анализа. 
Теоретической базой исследования послужили публикации отечественных и зарубежных ученых в области теории речевого воздействия Э. А. Бочаровой [1], О. С. Иссерс [2], Е. В. Клюева [5], В. Б. Кашкина [4], Н. И. Формановской [8], Р. Шпенглер [13] и др., в которых рассматривается прагмалингвистика коллективного и индивидуального речевого портрета, а также теории дискурса В. И. Карасика [3], Е. С. Кубряковой, О. В. Александровой [6] и др.

Практическая значимость исследования определяется возможностью использования его результатов в лекционно-семинарских курсах по прагмалингвистике, риторике, теории речевого воздействия, теории дискурса, а также при подготовке студентами курсовых и дипломных работ.

\section{Место протокольно-этикетных речей в семантическом пространстве дискурса}

В настоящее время существует довольно много работ, посвященных различным типам дискурса. При этом, на наш взгляд, одним из наименее исследованных типов дискурса остается официально-деловой дискурс в силу его клишированности и строгой приверженности языковым нормам по сравнению с другими типами дискурса. Безусловно, в рамках этого типа дискурса формируется множество разнообразных типов текстов, одним из которых является протокольно-этикетная речь, которая рождается в пространстве официальноделового дискурса и, как следствие, обладает всеми признаками этого типа дискурса.

Как очевидно, типология публичных речей в риторике представлена довольно широко, однако сам термин «протокольно-этикетная речь» функционирует лишь в типологии И. А. Стернина. Это является подтверждением того факта, что в риторической науке нет точной дефиниции понятия «протокольно-этикетная речь». Сам И. А. Стернин, используя этот термин, определяет протокольно-этикетные выступления как такие, которые «имеют целью соблюсти традиции общения в той или иной официальной ситуации, выполнить соответствующие требования этикета, ритуала» [7, с. 190]. В своей работе мы полагаем, что под протокольноэтикетной речью можно понимать особый тип текста, формирующийся в пространстве официальноделового дискурса в целях актуализации речевым субъектом конкретного события социальной значимости.

Поскольку в нашей работе мы исследуем протокольно-этикетную речь политических деятелей, становится совершенно очевидно, что в этих коммуникативных условиях данный тип речи будет иметь и признаки, характерные для политического дискурса.

На наш взгляд, можно утверждать, что в данном случае протокольно-этикетная речь находится в зоне интердискурсивного взаимодействия, то есть на пересечении официально-делового и политического дискурса.

\section{Типология речевых стратегий и тактик, используемых немецкими политиками в протокольно-этикетных речах}

В процессе нашего исследования мы пришли к выводу, что для такого типа речи, как протокольноэтикетная речь, характерны, в первую очередь, три универсальные стратегии, которые выделены у многих исследователей политического дискурса: стратегия формирования эмоционального настроя, стратегия аргументации и стратегия кооперации.

Следующей стратегией, которую мы посчитали необходимым выделить в рамках протокольно-этикетной речи, является достаточно известная и универсальная для политического дискурса стратегия самопрезентации. Однако в данных условиях она является достаточно специфичной, поскольку в рамках риторики эта стратегия считается нетипичной для протокольно-этикетной речи [9] и, следовательно, в нашем случае она приобретает «новую жизнь» в результате трансформации.

Далее мы полагаем возможным говорить о существовании в рамках протокольно-этикетной речи новой универсальной стратегии строгой регламентации речи, которая по своей сути нигде прежде не рассматривалась, но существование которой предполагается а priori в официально-деловом дискурсе.

Таким образом, нам удалось в процессе исследования выделить ряд универсальных стратегий разного ранга:

1) классические стратегии, выделенные в политическом дискурсе;

2) классическая стратегия, выделенная в политическом дискурсе, но наполненная новым содержанием, исходя из характеристик протокольно-этикетной речи как типа речи;

3) стратегия, существование которой предполагается характеристиками официально-делового дискурса, но исследование которой ранее нигде не осуществлялось.

Каждая речевая стратегия реализуется в определенных тактиках при помощи тех или иных языковых средств (см. Рис. 1).

Обратимся далее к рассмотрению каждой из указанных стратегий по степени их важности для данного типа речи.

Стратегия строгой регламентации речи выражается в соблюдении тех узуальных норм, которые регламентируют протокольно-этикетную речь как тип речи, и реализуется в виде таких тактик:

- тактика соблюдения формальных критериев, заключающаяся в структурировании протокольноэтикетной речи в соответствии с нормами и правилами официального стиля, что подразумевает в первую очередь трехчастную структуру (введение, основная часть, заключение); 


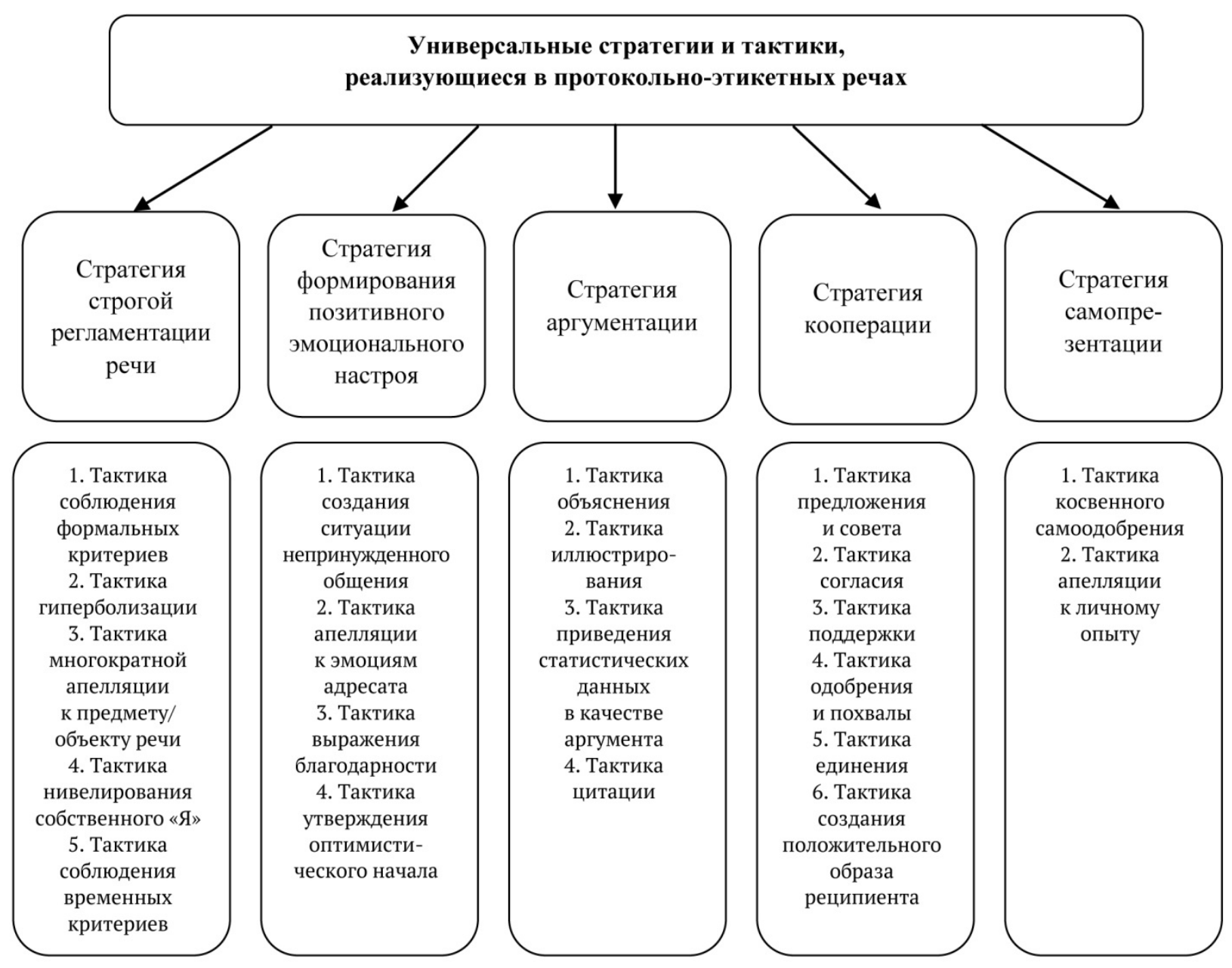

Рисунок 1

- тактика гиперболизации, используемая для идеализации сущностных свойств интерпретируемого в речи объекта или субъекта;

- тактика многократной апелляции к объекту/предмету речи, что проявляется в частотном номинировании речедеятелем предмета/объекта речи для концентрации на ней внимания слушателей (от 3 до 55 обращений в пределах одной протокольно-этикетной речи в зависимости от ее объема);

- тактика нивелирования собственного «Я», характеризующаяся двукратным, а в некоторых случаях трехкратным превышением употребления местоимения wir (мы) по сравнению с местоимением ісһ (я) в текстах протокольно-этикетных речей;

- тактика соблюдения временных критериев, предусматривающая достаточно ограниченный объем подобных речей. Однако нами было установлено, что на современном этапе данная тактика выходит из разряда универсальных в связи с нарушением речедеятелями временных рамок и увеличением временного интервала продолжительности речи (из проанализированных нами 160 речей только около 21\% соответствуют традиционному временному критерию в 3-5 минут) [Там же].

Главной задачей стратегии формирования позитивного эмоционального настроя является эмоциональное воздействие на адресата с намерением заставить его разделить испытываемые оратором чувства. С этой целью речевым субъектом используются такие тактики, как тактики создания непринужденного общения, апелляции к эмоциям адресата, выражения благодарности и утверждения оптимистического начала.

В качестве наглядного примера можно упомянуть тактику выражения благодарности, которая находит широкое использование в протокольно-этикетных речах не только с помощью выражения автоматического «спасибо», но и в искренней, человеческой благодарности. Рассмотрим фрагмент речи А. Меркель, посвященной приему штернзингеров.

Und ich möchte mich ganz herzlich beim Kanzleramtsminister Peter Altmaier bedanken, der heute einen Teil des Programms übernommen hat, weil ich nicht ganz so gut stehen kann und mehr liegen soll, wie man ja gelesen und jetzt auch gesehen hat [12]. / А я хотела бы от всей души поблагодарить министра Питера Альтмайера, который сегодня взял на себя часть программы, потому что я не могу долго стоять и должна больше лежать, как вы уже читали и видите сейчас (здесь и далее перевод автора статьи. - Е. Ц.).

В данном примере канцлер благодарит главу ведомства федерального канцлера, федерального министра по особым поручениям и своего друга П. Альтмайера за помощь в проведении мероприятия, поскольку 
в связи с травмой она не могла бы самостоятельно организовать его. Хотя А. Меркель и использует клишированный глагол sich bedanken (благодарить), она подкрепляет его интенсификатором ganz herzlich (от всего сердца) и очень подробным объяснением своего «сидячего» положения, тем самым демонстрируя не только вежливость, но и чувство искренней признательности своему коллеге за поддержку.

Стратегия аргументации является ключевой в любой речи политического дискурса, поскольку конечной целью каждого политика является убеждение слушателей в своей правоте. Основными способами ее реализации являются тактика объяснения, иллюстрирования, приведения статистических данных в качестве аргумента и тактика цитации.

Универсальной для протокольно-этикетных речей служит и стратегия кооперации, так как призыв к сплочению и сотрудничеству слушателей и оратора характерен для любого типа речи, особенно в политической сфере. Для продуктивного использования данной стратегии в своих речах немецкие политики употребляют тактики предложения и совета, поддержки, единения, одобрения и похвалы, создания положительного образа реципиента.

Например, бывший президент ФРГ Й. Гаук, обращаясь к руководству Индонезии, обещает, что Германия будет стимулировать ее действия, что его страна может и должна способствовать ее экономическому росту и благополучию.

Unser Land will Sie daher in Ihrer Haltung gern bestärken! <...> Wir können und müssen dazu beitragen, dass wirtschaftliches Wachstum nicht an der Substanz zehrt, dass natürliche Ressourcen geschont und möglichst viele Menschen davon profitieren [11]. / Поэтому наша страна хочет поддержать Вас в Ваших действиях! <...> Мы можем и должны способствовать тому, чтобы экономический рост имел хорошую опору, чтобы природные ресурсы были сохранены и как можно больше людей выиграли от этого.

Для реализации тактики Й. Гаук использует глаголы bestärken (усиливать, укреплять), beitragen (способствовать) и модальные глаголы долженствования и необходимости können (мочь, уметь) и müssen (должен), что позволяет ему не просто обещать поддержку, а вселить некую уверенность.

Что касается последней выделенной нами стратегии самопрезентации, необходимо подчеркнуть, что мы рассматриваем ее как новую универсальную стратегию в рамках протокольно-этикетной речи, поскольку традиционно, как это отмечалось ранее, этим речам присуща тактика нивелирования собственного «Я», рассмотренная нами выше в составе стратегии строгой регламентации речи. Согласно нашим исследованиям, протокольно-этикетные речи последних лет отличаются в этом смысле определенной амбивалентностью, поскольку параллельно с тактикой нивелирования собственного «Я» практически во всех протокольноэтикетных речах современных немецких политиков присутствует выделенная нами в рамках стратегии самопрезентации тактика косвенного самоодобрения, что говорит о приобретении данным типом речей более субъективного характера. Однако эти две тактики не являются взаимоисключающими: напротив, в рамках протокольно-этикетных речей они имеют взаимодополняющий характер.

Особенности диалектического взаимодействия тактик нивелирования собственного «Я» и косвенного самоодобрения можно проследить, в частности, на примере речи Й. Гаука, в которой он, говоря о Германии как о стране и как о народе, живущем в этой стране, и сообщая о положительных тенденциях ее развития, таким образом, косвенно одобряет не только свою работу, но и себя в качестве политического лидера этой страны, не используя личного местоимения ich (я). В лексическом плане, говоря об успешном выходе государства из экономического кризиса, Й. Гаук использует положительно окрашенный глагол теistern (справляться с чем-л.), усиленный частицами sogar (даже), sehr (очень) и наречиями gut (хорошо), stabil (стабильно) в рамках сравнения нынешнего состояния немецкого общества с другими европейскими странами:

Deutschland hat die Krise bisher gut gemeistert. Verglichen mit anderen Europäern geht es den meisten von uns wirtschaftlich gut, ja sogar sehr gut. Zudem ist Deutschland politisch stabil [10]. / Германия до сих пор хорошо справлялась с кризисом. По сравнению с другими европейцами, у большинства из нас в экономическом плане все хорошо, даже очень хорошо. Кроме того, Германия политически стабильна.

Следующей тактикой, присущей стратегии самопрезентации, мы считаем тактику апелляции к личному опыту, употребление которой позволяет оратору вовлечь слушателя в личные переживания, тем самым способствуя более яркой и запоминающейся подаче собственной личности в рамках своего выступления, хотя в традиционных риторических образцах протокольно-этикетной речи подобная речедеятельность должна носить достаточно сдержанный характер.

На лексическом уровне средствами проявления данной тактики служит частотное употребление указательного местоимения selbst (сам, самостоятельно) и прилагательных persönlich (лично), eigen (собственный), личного местоимения ісh (я) в различных формах, глаголов и словосочетаний с семантикой сотрудничества и сопричастности.

\section{Заключение}

Выводы. В процессе исследования мы установили, что под протокольно-этикетной речью можно понимать особый тип текста, формирующийся в пространстве официально-делового дискурса в целях актуализации речевым субъектом конкретного события социальной значимости. Поскольку в нашей работе материалом исследования послужили протокольно-этикетные речи политических деятелей, становится совершенно 
очевидно, что в этих коммуникативно-прагматических условиях данный тип речи будет иметь и признаки, характерные для политического дискурса. Таким образом, протокольно-этикетная речь имеет синтетический характер, находясь в зоне интердискурсивного взаимодействия на пересечении официально-делового и политического дискурсов.

Также результаты осуществлённого анализа свидетельствуют о том, что, несмотря на клишированность протокольно-этикетной речи и ее строгую регламентированность, немецкие политические деятели активно используют широкий спектр речевых стратегий и тактик для оказания определенного воздействия на адресата, а именно: стратегию строгой регламентации речи, существование которой предполагается характеристиками официально-делового дискурса; стратегию формирования эмоционального настроя, стратегию аргументации и стратегию кооперации, также универсальную для политического дискурса, но в целом нетипичную для протокольно-этикетной речи стратегию самопрезентации.

Перспективы дальнейшего исследования проблемы мы видим в дальнейшем исследовании вопросов теории и практики речевого воздействия в рамках лингвогендерологии и теории дискурса.

\section{Источники | References}

1. Бочарова Э. А. Политический дискурс как средство манипуляции сознанием: автореф. дисс. .... к. филол. н. Белгород, 2013. 23 с.

2. Иссерс О. С. Речевое воздействие: учеб. пособие для студентов. М.: Флинта; Наука, 2011. 224 с.

3. Карасик В. И. Дискурс // Социальная психолингвистика: хрестоматия / сост. К. Ф. Седова. М.: Лабиринт, 2007. С. 162-196.

4. Кашкин В. Б. Введение в теорию коммуникации: учеб. пособие. Воронеж: ВГТУ, 2000. 175 с.

5. Клюев Е. В. Речевая коммуникация. М.: ПРИОР, 1998. 224 с.

6. Кубрякова Е. С., Александрова О. В. Виды пространств текста и дискурса // Категоризация мира: пространство и время: мат-лы научной конференции / под ред. Е. С. Кубряковой. М.: МГУ имени М. В. Ломоносова, 1997. С. 16-28.

7. Стернин И. А. Введение в речевое воздействие. Воронеж: Истоки, 2001. 252 с.

8. Формановская Н. И. Речевое общение: коммуникативно-прагматический подход: учебник для студентов вузов. М.: Рус. яз., 2002. 216 с.

9. Цветкова Е. Б. Речевой портрет современных немецких политиков в аспекте прагмалингвистики (на материале текстов протокольно-этикетных речей): дисс. ... к. филол. н. Калининград: Балтийский федеральный университет имени Иммануила Канта, 2018. 267 с.

10. http://www.bundespraesident.de/SharedDocs/Reden/DE/Joachim-Gauck/Reden/2012/12/121225-Weihnachtsans prache.html (дата обращения: 15.05.2021).

11. http://www.bundespraesident.de/SharedDocs/Reden/DE/Joachim-Gauck/Reden/2013/03/130304-Indonesien-Staats bankett.html;jsessionid=48A1B3992EDAEC60AF0ED94D5037795F.2_cid285 (дата обращения: 15.05.2021).

12. https://www.bundesregierung.de/ContentArchiv/DE/Archiv17/Reden/2013/01/2013-01-04-sternsinger.html (дата обращения: 15.05.2021).

13. Spengler R. Menschengewinner: die besten Strategien, mit anderen ins Gespräch zu kommen und sie von sich zu überzeugen. München: Ariston-Verlag, 2012. 182 S.

\section{Информация об авторах | Author information}

RU Цветкова Екатерина Борисовна ${ }^{1}$, к. филол. н.

${ }^{1}$ Военный университет Министерства обороны Российской Федерации, г. Москва

EN Tsvetkova Ekaterina Borisovna ${ }^{1}, \mathrm{PhD}$

${ }^{1}$ Military University of the Ministry of Defense of the Russian Federation, Moscow

${ }^{1}$ e.tsvetkova.kgd@yandex.ru

\section{Информация о статье | About this article}

Дата поступления рукописи (received): 15.04.2021; опубликовано (published): 31.05.2021.

Ключевые слова (keywords): протокольно-этикетная речь; коммуникативные стратегии; коллективный речевой портрет; политический дискурс; ceremonial speech; communicative strategies; collective speech portrait; political discourse. 